\title{
Donate or not to donate if with visceral obesity
}

\author{
Baris D. Yildiz ${ }^{1} \mathbb{D}$
}

Received: 24 December 2018 / Accepted: 31 December 2018 / Published online: 4 January 2019

(c) Springer-Verlag GmbH Germany, part of Springer Nature 2019

\section{Dear Editor,}

We read with great interest the article titled "Visceral obesity in Asian living kidney donors significantly impacts early renal function after donor nephrectomy" by Pek et al. [1]. The authors analyzed whether visceral obesity (VO) had an impact on early renal function in kidney donors. We have two objections about this study.

First, by the time when the estimated glomerular filtration rates (GFR) were calculated did the patients still have VO? If so, it would be a better approach to use a calculation method adjusted for body mass index. This is secondary to the fact that most formulas in general use for estimation of GFR are not appropriate for use in obese populations and, thus, might mislead the interpretation of GFR [2].

Second, it is stated in the particular article that hypertension and hyperlipidemia preoperatively did not differ between the groups which means certain patients were not ideal donors. This raises question whether the recipients of these suboptimal donors had any issues with their kidney grafts such as delayed graft function, etc. If we knew the answer to this concern, we might rule that we should exclude patients with $\mathrm{VO}$ in the first place when it comes to kidney donation.

Author contributions BDY: manuscript writing/editing.

\section{Compliance with ethical standards}

Conflict of interest There is no conflict of interest concerning this article.

Ethical statements There is no involvement of human subject or animals for this work and thus, informed consent is not applicable.

\section{References}

1. Pek GXW, Ngoh CLY, Teo BW, Vathsala A, Goh BYS, Yong CHR, Raman L, Tiong HY (2018) Visceral obesity in Asian living kidney donors significantly impacts early renal function after donor nephrectomy. World J Urol. https://doi.org/10.1007/ s00345-018-2566-2. [(Epub ahead of print) PubMed PMID: 30456710]

2. Nguyen MT, Fong J, Ullah S, Lovell A, Thompson CH (2015) Estimating glomerular filtration rate in obese subjects. Obes Res Clin Pract 9(2):152-157
Baris D. Yildiz

baris104@yahoo.com

1 Ankara Numune Teaching Hospital General Surgery, 06100 Sihhiye, Ankara, Turkey 